
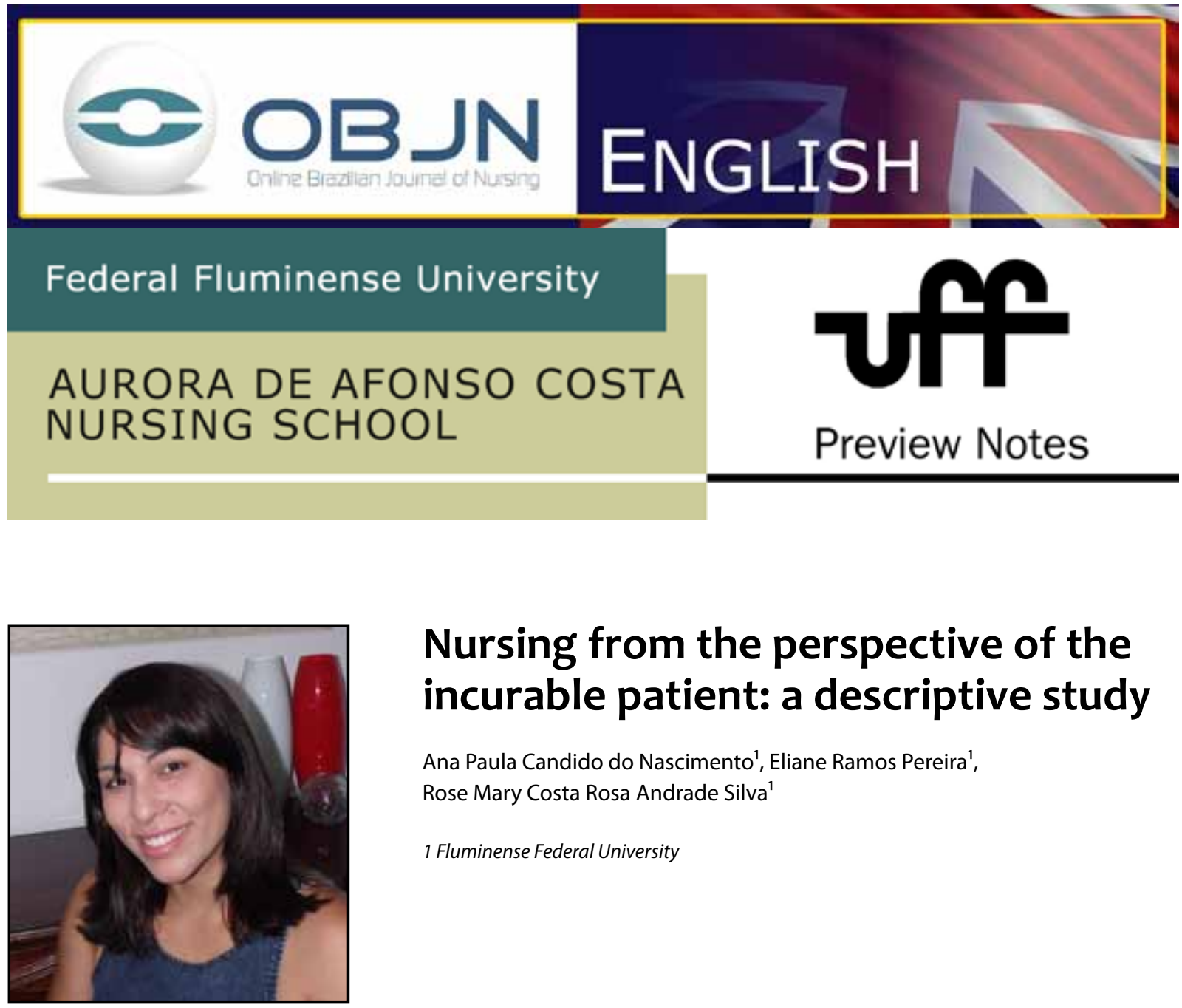

\title{
Nursing from the perspective of the incurable patient: a descriptive study
}

\author{
Ana Paula Candido do Nascimento', Eliane Ramos Pereira', \\ Rose Mary Costa Rosa Andrade Silva' \\ 1 Fluminense Federal University
}

\section{ABSTRACT}

Problem: When the failure of conventional means of treating the patient is confirmed, the challenges and lack of preparation on the part of nurses in providing ways to deal with the patient's suffering may reflect directly on the quality of care provided, especially to those who have no possibility of a cure. Aims: To understand the perceptions of patients with regard to the impossibility of a cure and experiences in nursing care; to describe the emotional needs of these patients and the perspectives of their nursing care; to develop a video based on the experiences and needs of the incurable patient, and perspectives of nursing interventions for the in-service training of nurses. Method: A descriptive qualitative study, using semi-structured interviews and phenomenology as a philosophical reference.

Descriptors: Nursing Care; Death; Quality of Life. 


\section{SITUATION AND ITS SIGNIFICANCE}

The technological progress of medicine has transformed the phenomenon of death into something shameful and a concept to be denied. Studies into nursing care before death and dying in hospitals reveals a defensive stance on the part of the healthcare team, establishing a model of the denial of reality that prevents the professional from facing the inevitability of the finite process of the patient ${ }^{(1)}$. In this model, "the health care is impersonal, mechanical and aseptic" ${ }^{\prime \prime(2)}$.

Thus, it is necessary to know the perceptions of the incurable patient with regard to the dying process. The research question and the problem dealt with in this study is as follows: What are the perceptions of the incurable patient with regard to nursing care?

\section{GUIDING QUESTIONS}

- What are the perceptions of the patients in terms of their mortality, and about nursing care regarding their emotional demands?

- What are the prospects of emotional care for such a patient?

\section{AIMS}

- To understand the perceptions of patients about the impossibility of healing and their experiences of nursing care;

- To describe the emotional needs of these patients and their perspectives of their nursing care;

- To develop a video based on the experiences and needs of the incurable patient, and their perspectives with regard to nursing interventions, for use in the in-service training of nurses.

\section{METHOD}

We decided to perform a descriptive field study, using a qualitative approach and semi-structured interviews to collect data. The theoretical and methodological approach to be used will be Merleau-Ponty's phenomenology, in order to understand the existential experience of the patients. The study will produce a documentary-style film that is characterized by portraying a specific event or fact, showing the reality more broadly and in its interpretative extension, presenting new ways of seeing the world. The documentary aims to motivate nurses regarding the care of patients' basic needs.

The research will be performed in the clinical department of a medium-sized municipal hospital, serving the population of Duque de Caxias / RJ and surroundings, in the period between March and August 2015.

Patients to be included are incurable ones who have a chronic illnesses such as chronic renal failure, HIV / AIDS, cancer and other diseases, aged 18 years and over, hospitalized at the clinic regardless of the length of stay. As an exclusion criteria, patients who are in no physical, mental or emotional condition for the interview are to be left out of the study.

Participants will be interviewed according to their availability and agreement. There will be no interference in their medical care or rest, and the interview can be interrupted/canceled at any time with no harm to the research or the participants. Regardless of this being a qualitative study, it is expected that we will sample at least four patients in order to show the deepening of the phenomenon, and data collection will be closed with the saturation of the information obtained.

After identification at the medical clinic of the incurable patients, an invitation to participate in the interviews will be made. After clarifying 
any doubts, the consent form will be presented and signed. Upon acceptance, interviews will be conducted and patients will be free to give their testimonies. In terms of the treatment of the data collected, Bardin analysis will be used in order to categorize data, which will be interpreted with the support of the phenomenology of Merleau-Ponty.

After the perceptual dimensions of the patients, experienced in the light of the impossibility of a cure, and also their perceptions with regard to the nursing care received is unveiled, we will begin the preparation of the video as an educational tool. This will be implemented with the nurses, using a focus group to obtain their perspective. The video aims to raise awareness and improve in-service education for the nurses regarding the needs detailed in the reports of the patients, and the proposed connections to the provision of care based on the emotional dimensions of the patients.

The project was submitted to the Antonio Pedro University Hospital Ethics Research Committee and was approved by CEP Opinion Id register 836511 .

\section{REFERENCES}

1. Chagas MS, Merhy EE, Abrahão AL, Cerqueira $M P$, Silva $E$. The caring in face of the finiteness in the hospital institutions: adescriptive study. Online braz j nurs [Internet]. 2013 Oct [cited year mouth day]; 12 Suppl: 719-21. Available from: http://www.objnursing.uff.br/index.php/ nursing/article/view/4546. doi: http://dx.doi. org/10.5935/1676-4285.20134546.

2. Silva WCBP, Silva RMCRA, Pereira ER, Silva MA, Marins AMF, Sauthier M. Nursing team perception of oncological palliative care: a phenomenological study. Online braz j nurs [internet]. 2014 Mar [cited year mouth Day]; 13 (1): 72-81. Available from: http://www.objnursing.uff.br/index.php/ nursing/article/view/4125).

3. Merleau-Ponty, M. Fenomenologia da percepção 1908-1961- 2- ed. - São Paulo: Martins Fontes, 2011

All authors participated in the phases of this publication in one or more of the following steps, in According to the recommendations of the International Committee of Medical Journal Editors (ICMJE, 2013): (a) substantial involvement in the planning or preparation of the manuscript or in the collection, analysis or interpretation of data; (b) preparation of the manuscript or conducting critical revision of intellectual content; (c) approval of the versión submitted of this manuscript. All authors declare for the appropriate purposes that the responsibilities related to all aspects of the manuscript submitted to OBJN are yours. They ensure that issues related to the accuracy or integrity of any part of the article were properly investigated and resolved. Therefore, they exempt the OBJN of any participation whatsoever in any imbroglios concerning the content under consideration. All authors declare that they have no conflict of interest of financial or personal nature concerning this manuscript which may influence the writing and/or interpretation of the findings. This statement has been digitally signed by all authors as recommended by the ICMJE, whose model is available in http://www. objnursing.uff.br/normas/DUDE_eng_13-06-2013.pdf

Received: 07/17/2014

Revised: 10/23/2014

Approved: $10 / 23 / 2014$ 